\title{
Resposta imune humoral na paracoccidioidomicose experimental em camundongos ddY
}

\section{Humoral immune response in experimental ddY mice paracoccidioidomycosis}

\author{
Berenice Tomoko Tatibana ${ }^{1}$; Ayako Sano²; Jun $\mathrm{Uno}^{2}$; Yuzuru Mikami²; \\ Makoto Miyaji ${ }^{2}$; Kazuko Nishimura2 ${ }^{2}$ Eiko Nakagawa Itano $^{3 *}$
}

\section{Resumo}

A paracoccidioidomicose (PCM) é uma micose sistêmica, restrita à América Latina, com maior incidência no Brasil. O camundongo ddY tem sido empregado como modelo murino de PCMe, no entanto, não há informações a respeito da resposta imune desse animal frente à infecção. $O$ presente estudo tem como objetivo avaliar a resposta imune humoral específica para o principal antígeno, gp43, do fungo Paracoccidioides brasiliensis, em camundongos ddY infectados com a cepa virulenta $\mathrm{Pb} 18$. Foram realizadas análises da antigenemia $\mathrm{e}$ histopatológico em vários órgãos e em diferentes tempos pós-infecção. Os resultados obtidos demonstraram aumento nos níveis de IgG anti-gp43 nos dias 14, 17, 21, 24, 28 e 56 pós-infecção e aumento no nível de gp43 solúvel aos 28 dias pós-infecção. As células fúngicas foram detectadas em todos os órgãos analisados (cérebro, coração, pulmão, fígado, baço e rim) e em todos os períodos. As lesões granulomatosas tornaramse predominantes 14 dias pós-infecção. Os resultados evidenciaram que o camundongo ddY produz resposta imune humoral frente ao principal antígeno de $P$. brasiliensis, apresentando-se elevado até 56 dias pósinfecção. A redução do nível de gp43 solúvel na fase crônica, supostamente devido ao início do controle da infecção, requer estudos complementares adicionais.

Palavras-chave: Paracoccidioides brasiliensis, paracoccidioidomicose experimental, DDY, resposta imune

\begin{abstract}
Paracoccidioidomycosis (PCM) is a systemic mycosis, restrict to Latin America, with higher incidence in Brazil. ddY mice have been used as experimental PCM model, although there is no data regarding immune response. The aim of the present study was evaluated specific humoral response against the main specific antigen of the fungal Paracoccidioides brasiliensis, the gp43, in ddY mice infected with virulent $\mathrm{Pb} 18$. Antigenemia analysis and histophatological exam in several organs were performed in different time postinfection The results showed increased levels of anti-gp43 IgG on days 14, 17, 21, 24, 28 and 56 post-infection and increased levels of soluble gp-43 on day 28 post-infection. The fungal cells were detected in all organs analyzed (brain, heart, lung, liver, spleen and kidney) in all investigated periods. The granulomatous lesions became predominant 14 days after infection. The results evidence that ddY mice produce humoral immune response to main $P$. brasiliensis antigen, with high levels until 56 days after infection. Further studies are needed to show that reduction of soluble gp43 in chronic phase correlates with infection control.

Key words: Paracoccidioides brasiliensis, experimental paracoccidioidomycosis, DDY, immune response

1 Aluna de Doutorado do Programa de Pós-graduação em Microbiologia, Universidade Estadual de Londrina (UEL).

2 Research Center of Pathogenic Fungi and Microbial Toxicoses, Chiba University, Chiba, Japão.

3 Departamento de Ciências Patológicas, Centro de Ciências Biológicas, UEL, Campus Universitário, CEP 86051-990, Londrina, Paraná, Brasil. E-mail: itanoeiko@hotmail.com
\end{abstract}

* Autor para correspondência 


\section{Introdução}

A paracoccidioidomicose (PCM) é uma doença granulomatosa crônica de ocorrência endêmica no Brasil, cujo agente etiológico é o fungo dimórfico Paracoccidioides brasiliensis. A epidemiologia da infecção é intimamente relacionada com indivíduos que exercem atividades rurais, principalmente o cultivo de café (SILVA-VERGARA; MARTÍNEZ, 1998).

É considerada como a oitava causa de mortalidade por doença predominantemente crônica ou repetitiva entre as patologias infecciosas ou parasitárias, e a mais elevada taxa de mortalidade entre as micoses sistêmicas no Brasil, não possuindo, entretanto, intervenção terapêutica específica, estes dados revestem de importância estudos que elucidem a relação parasitohospedeiro (COUTINHO et al., 2002).

Sendo assim, a imunidade humoral vem sendo estudada em seres humanos e em animais de laboratório por sua associação com o aumento da disseminação da doença e a gravidade das manifestações clínicas (BIAGIONI et al., 1984; CANO et al., 1995; VAZ et al., 1992).

$\mathrm{Na} \mathrm{PCM}$ experimental, diversos modelos animais têm sido empregados na tentativa de mimetizar a PCM humana e, dentre estes, o mais empregado tem sido o modelo murino (COELHO et al., 1982; BRUMMER; CASTANEDA; RESTREPO, 1993).

Os camundongos podem ser classificados em muito resistente $(\mathrm{A} / \mathrm{Sn})$, resistente $(\mathrm{C} 3 \mathrm{H} / \mathrm{He})$, intermediário $(\mathrm{C} 3 \mathrm{H} / \mathrm{HeB}, \mathrm{C} 57 \mathrm{~B} 1 / 10, \mathrm{CBA}, \mathrm{BALB} /$ c) e susceptível (B10.A, B10D2/oSn e B10D2/nSn) quanto a sua suscetibilidade à infecção pelo $P$. brasiliensis. Foi demonstrado que, independente da rota de inoculação, a produção de anticorpo total específico pelos camundongos suscetíveis é mais precoce e com titulação mais alta quando comparados com os de linhagem considerada resistente (CALICH et al, 1985; VAZ et al., 1992; SINGER-VERMES et al., 1993). Diante destes resultados acreditamos que o modelo murino de PCM é um instrumento capaz de auxiliar na elucidação dos mecanismos imunológicos envolvidos nesta micose sistêmica.
O camundongo ddY, apesar de ser utilizado para o estudo de diferentes aspectos da PCM (SANO; MIYAJI; NISHIMURA, 1991; ITANO et al., 2002), não possui até o momento, dados imunológicos mais específicos . O presente estudo propõe a análise da resposta imune humoral com a utilização de antígeno específico imunodominante de $P$. brasiliensis, a gp43, em camundongos ddY.

\section{Material e Métodos}

\section{Paracoccidioides brasiliensis}

Para a infecção experimental foi utilizado o isolado $\mathrm{Pb} 18$ (=IFM41621), mantido em temperatura ambiente em ágar batata dextrosado (Difco, MO, EUA) e subcultivado duas vezes ao ano. Anteriormente à sua utilização, o isolado foi semeado em meio ágar infuso cérebro-coração dextrosado (BHI, Difco, EUA) e mantido a $35^{\circ} \mathrm{C}$ para obtenção da forma leveduriforme. Utilizou-se cultivo de cinco dias. As células fúngicas foram ressuspensas em solução salina estéril e ajustadas para concentração de $5 \times 10^{6}$ células $/ \mathrm{mL}$.

Para obtenção do antígeno somático utilizado na cromatografia para purificação da gp43, o isolado utilizado foi o $\mathrm{Pb}$ B-339 com subcultivo de cinco dias em ágar saboraud (Micromed, Rio de Janeiro, Brasil).

\section{Animais}

Camundongos machos ddY, livres de patógenos específicos (SPF), de seis semanas (Nihon SLC Co, Ltda, Shizuoka, Japão) foram mantidos em ambiente climatizado $\left(25 \pm 1^{\circ} \mathrm{C}\right)$ e controlado (umidade $55 \pm 5 \%$ ), alimentados ad libidum.

\section{Purificação da gp43}

O antígeno somático foi obtido através da suspensão de aproximadamente 10,30 g (peso seco) de células do isolado $P b$ B-339 em 15 mL de solução salina-fosfato tamponada (PBS) $(\mathrm{pH} 7,4)$ estéril, 
seguido de ruptura manual por maceração com utilização de nitrogênio líquido. O produto obtido foi centrifugado a $300 \mathrm{~g}$ por 20 minutos a $4{ }^{\circ} \mathrm{C}$. O sobrenadante foi coletado, fez-se a adição de $0,5 \mathrm{mM}$ de fluoreto de fenilmetanosulfonil (PMSF; SigmaAldrich, St. Louis, Missouri, EUA). A cromatografia de afinidade em Affigel-10 (Bio-Rad Laboratories, Hercules, CA, EUA) utilizou anticorpo monoclonal anti-gp43 como ligante específico. A gp43 foi eluida em 0,1M glicina-HCl, pH 2,8 e neutralizada em seguida com tampão TRIS 2M, pH 9,0. As frações $(1,0 \mathrm{~mL})$ coletadas foram submetidas à espectrofotometria a $280 \mathrm{~nm}$. A partir de um pool das frações com absorbâncias mais altas, foi realizada diálise em PBS 0,15M. Posteriormente foi determinada a concentração protéica pelo reagente de Folin (LOWRY et al., 1971).

\section{Infecção experimental}

Oito grupos, constituídos de 5 camundongos, exceto o grupo de 56 dias e o controle normal não infectado, com 8 e 4 camundongos, respectivamente; foram formados. Todos os grupos receberam $0,2 \mathrm{ml}$ de solução salina contendo $10^{6}$ células de $P$. brasiliensis na fase leveduriforme, por via endovenosa no dia. Os animais dos grupos foram sacrificados nos dias 7, 10, 14, 17, 21, 24, 28 e 56 pós-infecção e amostras de sangue, pulmão, cérebro, coração, fígado, baço e rim foram coletados dos grupos infectados conforme as normas adotadas pelo Comitê de Sanidade Animal da Faculdade de Medicina, Universidade de Chiba, Japão. No grupo controle, dois camundongos foram mantidos por 28 dias e outros dois por 56 dias, nas mesmas condições.

\section{Obtenção de $\operatorname{Ig} G$ de coelho anti-gp43}

O preparado purificado de gp-43 foi injetado por via subcutânea em coelhos. A primeira imunização foi feita com adjuvante completo de Freund ( $800 \mu \mathrm{L}$ de adjuvante com $800 \mu \mathrm{L}$ de gp43). Para a segunda e a terceira imunizações, realizados com intervalo de duas semanas e com adjuvante incompleto de Freund, foi utilizado o mesmo esquema de imunização. O soro hiperimune obtido foi purificado em coluna de Sefarose-G e a concentração protéica determinada pelo reagente de Folin (LOWRY et al., 1971).

\section{ELISA para determinação da antigenemia}

Placas de 96 orifícios foram adsorvidas com IgG de coelho anti-gp43, na concentração de $12 \mu \mathrm{g} / \mathrm{mL}$, em tampão carbonato-bicarbonato ( $\mathrm{pH} 9,6)$. Após 1 hora de incubação a $37^{\circ} \mathrm{C}$ as placas foram deixadas por uma noite a $4^{\circ} \mathrm{C}$. Depois de quatro lavagens realizadas em tampão de lavagem constituído por PBS, 0,05\% Tween 20, 0,05\% leite desnatado (Molico® Nestlé, Brasil), as placas foram bloqueadas por uma hora em tampão de bloqueio (PBS, 0,05\% Tween 20,5\% leite desnatado), à temperatura ambiente. Em seguida foram adicionadas amostras de plasma (100 $\mu \mathrm{L} /$ orifício, diluídas 1/10 em PBS, $0,05 \%$ leite desnatado) dos camundongos infectados experimentalmente com $P$. brasiliensis e as placas foram incubadas por uma hora a $37^{\circ} \mathrm{C}$; em seguida adicionou-se anticorpo monoclonal anti-gp43 $(20 \mu \mathrm{g} /$ $\mathrm{ml}$ ) por uma hora a $37^{\circ} \mathrm{C}$. As placas foram novamente lavadas e incubadas com anti-IgG de camundongo conjugado à peroxidase (Sigma Chemical Co., St. Louis, MO, EUA) na diluição de 1:4000 em PBS, por uma hora a $37^{\circ} \mathrm{C}$. Após adição de $100 \mu \mathrm{L} /$ orifício de solução reveladora constituída por $5 \mathrm{mg}$ de cromógeno o-fenildiamino-dihidro-cloreto (OPD), 10 $\mathrm{ml}$ de tampão ácido cítrico fosfato $(\mathrm{pH} 4,5)$ e $10 \mathrm{~mL}$ de $\mathrm{H}_{2} \mathrm{O}_{2 ;}$ a reação foi interrompida com $50 \mu \mathrm{L} /$ orifício de $4 \mathrm{~N} \mathrm{H}_{2} \mathrm{SO}_{4}$ seguida de leitura da densidade óptica a $492 \mathrm{~nm}$ (Multiskan EX reader, Labsystems, Helsinki, Finlândia).

\section{Elisa para determinação de anticorpo específico}

Placas de 96 orifícios foram adsorvidas com gp43 purificada $(25 \mu \mathrm{g} / \mathrm{ml})$ diluída em tampão carbonato bicarbonato, pH 9,6. Após 1 hora de incubação a $37^{\circ} \mathrm{C}$ as placas foram deixadas por uma noite a $4^{\circ} \mathrm{C}$. 
Seguindo-se protocolo descrito no item anterior, após bloqueio e lavagens, incubou-se o plasma diluído (1:100 em PBS, 0,05\% leite desnatado) por uma hora. Após novas lavagens, incubou-se com a anti- IgG camundongo conjugado à peroxidase (Sigma Chemical Co., St. Louis, MO, USA) diluída de 1:4000 em $\mathrm{PBS}$, por uma hora à $37^{\circ} \mathrm{C}$. A revelação, interrupção da reação e leitura das placas seguiram os procedimentos descritos anteriormente.

\section{Exame histopatológico}

Os órgãos removidos dos camundongos foram imediatamente submetidos à fixação em solução de formalina a $10 \%$ por um período mínimo de 48 horas, processados rotineiramente para a preparação em cortes parafinados e corados por PAS (ácido periódico de Schiff) e analisados por microscopia óptica.

\section{Análise estatística}

As comparações estatísticas foram feitas por meio de análise de variância (ANOVA) e Teste de Tukey. Todos os valores são relatados em termos de Média e Desvio Padrão da média, com valores significativos quando $\mathrm{p}<0.05$.

\section{Resultados}

\section{ELISA para determinação da antigenemia}

Os níveis da gp-43 solúvel (Figura 1), expressos em valores de DO pelo ELISA, tiveram um significativo aumento no plasma analisado no $28^{\circ}$ dia pós-infecção $(0,176 \pm 0,090$ em relação a $0,081 \pm$ $0,001$ do grupo controle, $\mathrm{p}<0.05)$; não sendo estatisticamente significativo nos dias $7,10,14,17$, 21 e 56 pós-infecção $(0,097 \pm 0,003 ; 0,096 \pm 0,010$; $0,088 \pm 0,006 ; 0,084 \pm 0,004 ; 0,093 \pm 0,019$ e $0,101 \pm$ 0,021 , respectivamente; em relação a $0.081 \pm 0.001$ do grupo controle, $\mathrm{p}<0.05$ ).

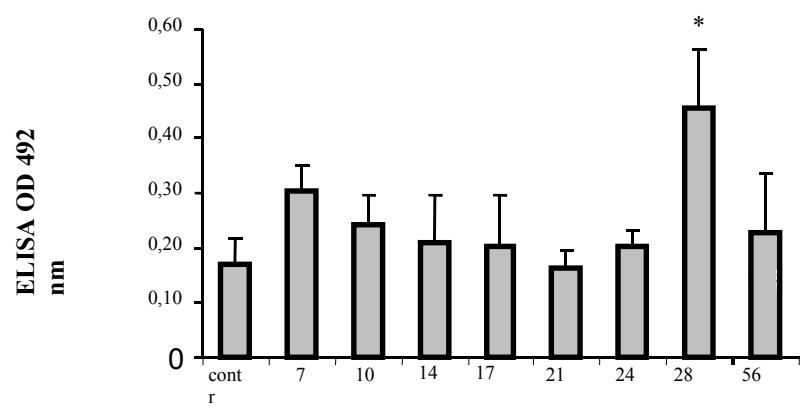

Figura 1. Concentração de gp-43 solúvel, expressos em DO a $492 \mathrm{~nm}$, obtidos por ELISA, em camundongos ddY com 7, 10, 14, 17, 21, 24, 28 e 56 dias pós-infecção por Pacoccidioides brasiliensis. (Contr=grupo controle). As barras horizontais mostram média \pm desvio padrão. (*valor estatisticamente significativo, $\mathrm{p}<0.05$ ).

Elisa para determinação de anticorpo específico

Para os resultados expressos em DO para o título de IgG anti-gp43 (Figura 2) observam-se um acréscimo nos dias $14,17,21,24,28$ e 56 pósinfecção $(0,465 \pm 0,021 ; 0,477 \pm 0,039 ; 0,492 \pm 0,044$; $0,515 \pm 0,071 ; 0,586 \pm 0,023 ; 0,640 \pm 0,085$; respectivamente) em relação ao grupo controle $(0,351 \pm 0.017), \mathrm{p}<0.05$. Nos dias 7 e $10(0,386 \pm$ $0,012$ e $0,382 \pm 0,015)$ não houve diferença estatística significativa em relação ao grupo controle $(0,351 \pm$ 0.017), $\mathrm{p}<0.05$.

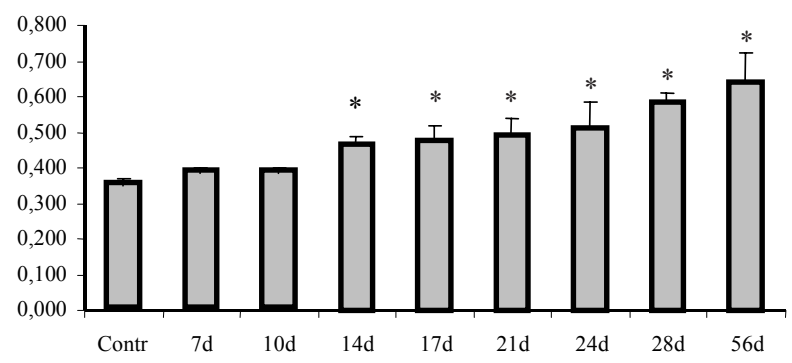

Figura 2. Resultados de IgG anti-gp43, expressos em DO a $492 \mathrm{~nm}$, obtidos por ELISA, em plasma de camundongo ddY, em 7, 10, 14, 21, 24, 28 e 56 dias pós-infecção por Pacoccidioides brasiliensis. As barras horizontais representam a média \pm desvio padrão. (*valores estatisticamente significativos, $\mathrm{p}<0.05)$. (Contr. $=$ grupo controle). 


\section{Exame histopatológico}

Foram detectadas células fúngicas em todos os órgãos avaliados. As lesões granulomatosas no pulmão foram predominantes no $17^{\circ}$ dia pós-infecção e, no $56^{\circ}$ dia pós-infecção, notou-se a presença de lesões granulomatosas com perda da camada mononuclear periférica. Nos períodos iniciais da infecção, outros órgãos como o fígado, rim e baço mostraram poucos sinais de infecção, tornando detectável após 7 dias e predominante ao $17^{\circ}$ dia.
Neste mesmo período, as lesões no rim tornaram-se granulomatosas com ou sem a presença de células fúngicas. As lesões no cérebro, coração e pulmão foram numerosas no $56^{\circ}$ dia, havendo invasão direta do parênquima pelo P. brasiliensis, corado fortemente pelo PAS, nas lesões do coração e cérebro (Figura 3). De forma geral, as lesões granulomatosas foram predominantes entre o $14^{\circ}, 24^{\circ}$ e $28^{\circ}$ dia após-infecção, havendo um aglomerado de lesões granulomatosas com camada contínua de células mononucleares e granulomas compactos.

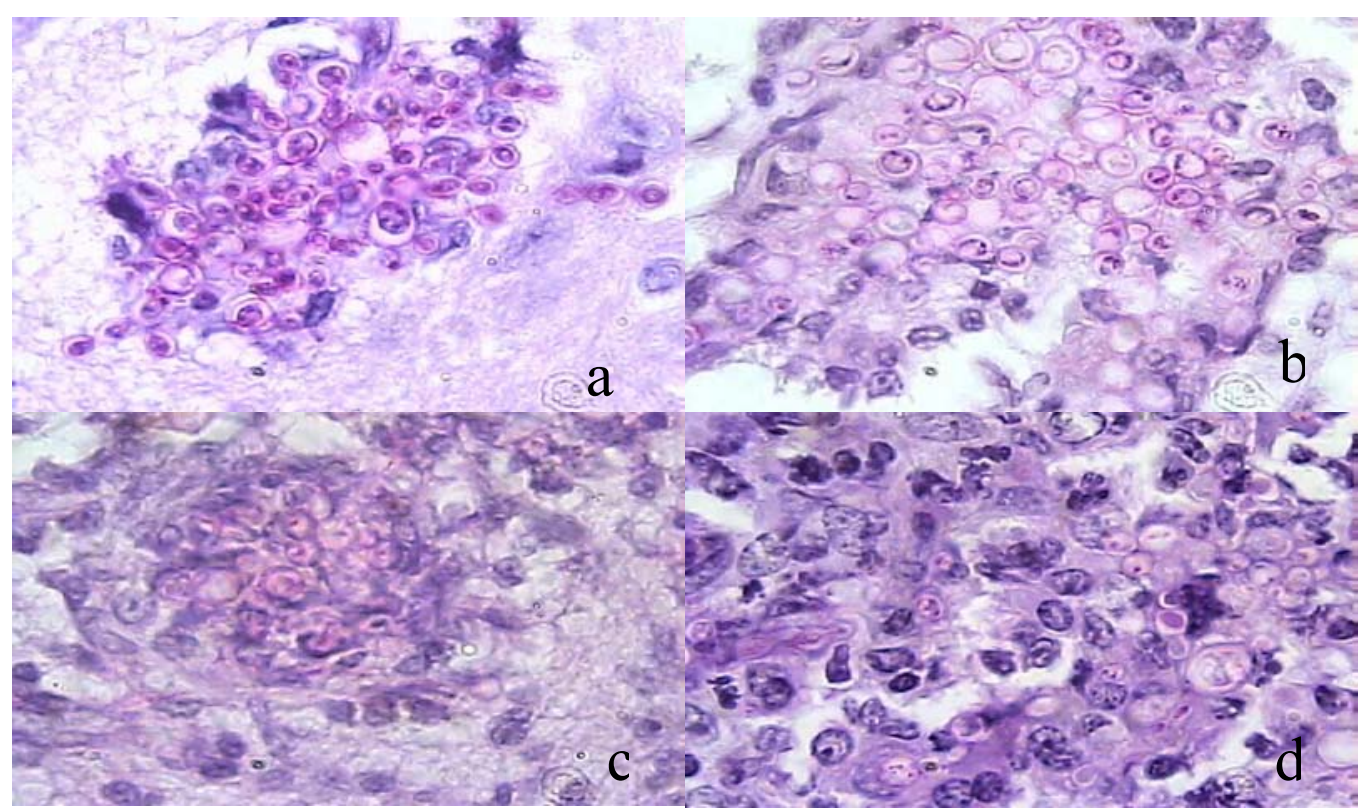

Figura 3. Cortes de cérebro demonstrando células fúngicas em lesões granulomatosas em 7 dias (a), 14 dias (b), 21 dias (c) e 56 dias (d) pós-infecção pelo fungo Pacoccidioides brasiliensis (coloração por PAS).

\section{Discussão}

Para a compreensão dos mecanismos imunes ativados durante a infecção por $P$. brasiliensis, é importante estabelecer um modelo murino susceptível e que seja o mais próximo possível da PCM humana. Isso torna a avaliação do modelo de PCM em camundongos ddY um desafio importante.

$\mathrm{Na} \mathrm{PCM}$, a produção de anticorpos específicos não é protetora. De fato, ela representa um comportamento que leva a um mau prognóstico da doença. O aumento no nível de anticorpo anti-gp43, tem sido demonstrado tanto em seres humanos quanto na PCM experimental, utilizando camundongos susceptíveis como o B.10A e o swiss (MENDESGIANNINI et al., 1990; VAZ et al., 1992; MIURA, 2001; RAMOS et al., 2005). Concordante com a literatura, também foram encontrados níveis elevados de anticorpos anti-gp43 pós-infecção por $P$. brasiliensis no camundongo ddY utilizado no presente estudo.

$\mathrm{Na}$ fase inicial da fungemia, considerando a via de inoculação endovenosa, não houve aumento estatístico significativo da gp43 solúvel. Isto pode estar relacionado à capacidade da gp43 solúvel de ligar-se a receptores de tecidos e células do hospedeiro (VICENTINI et al., 1995). Outra 
possibilidade pode ser a eliminação pela urina, já detectada em humanos e em camundongos (SALINA et al., 1998; RAMOS et al., 2005).

A detecção de altos níveis da gp-43 solúvel após 28 dias de infecção é um dado relevante detectado no presente estudo, já que pode apontar uma atividade maior do fungo in vivo ou, inversamente, uma maior neutralização pelo sistema imune do hospedeiro nesse período avaliado. Estudos complementares são requeridos para elucidação destas hipóteses.

A diminuição da concentração de gp43 solúvel no $56^{\circ}$ dia pós-infecção pode representar também um processo de neutralização pelos anticorpos do hospedeiro. Os dados de literatura com camundongos swiss e BALB/c, avaliados no mesmo período de 56 dias, apontam diferentemente, para um aumento na concentração de gp43 solúvel (RAMOS et al., 2005; PAVANELLI, 2006). Esta diferença poderia ser devido a maior resistência do camundongo ddY, uma vez que tanto a cepa quanto a quantidade de inóculos utilizados foram iguais.

Modelos murinos susceptíveis produzem lesões disseminadas em diferentes órgãos e tecidos enquanto os resistentes produzem lesões benignas com pequeno número de granulomas circunscritos (CALICH et al., 1985; SINGER-VERMES et al., 1995). No presente trabalho, observou-se a disseminação da infecção nos órgãos estudados e a formação de numerosos granulomas. Especificamente, no pulmão, 56 dias pósinfecção, notou-se a presença de lesões granulomatosas com perda da camada mononuclear periférica o que poderia levar a disseminação do fungo. Todavia, a diminuição da gp43 solúvel não é compatível com a formação deste tipo de granuloma, o que sugere a necessidade de estudos adicionais com maior tempo de duração da infecção, utilizando também outros parâmetros de disseminação ou controle da doença.

\section{Conclusões}

O camundongo ddY utilizado no estudo produziu resposta imune humoral antígeno específico em relação à gp43 de $P$. brasiliensis. Estudos adicionais são requeridos para verificar se a redução no nível da gp43 solúvel na fase crônica correlaciona-se ao início do controle da infecção.

\section{Agradecimentos}

Ao Ministério da Educação, Ciência, Esportes e Cultura do Japão, a CPG/UEL, FINEP e Fundação Araucária pelo suporte financeiro.

Aos professores Audrey Márquez de Souza e Édio Vizoni; aos técnicos Mári Sumigawa Kaminami e Nilson de Jesus Carlos e ao Dr. Rodolfo Ernani Kameo pela colaboração na conclusão do trabalho.

\section{Referências}

BIAGIONI, L.; SOUZA, M. J.; CHAMMA, L. G.; MENDES, R. P.; MARQUES, S. A.; MOTA, N. G. S.; FRANCO, M. Serology of paracoccidioidomycosis. II. Correlation between class-specific antibodies and clinical forms of the disease. Transactions of the Royal Society of Tropical Medicine and Hygene, Londres, v.78, n.5, p.617-621, 1984.

BRUMMER, E.; CASTANEDA, E.; RESTREPO, A. Paracoccidioidomycosis: an update. Clinical Microbiology Reviews, Washington, v.6, n.2, p.89-117, 1993.

CALICH, V. L.; SINGER-VERMES, L. M.; SIQUEIRA, A. M.; BURGER, E. Susceptibility and resistance of inbred mice to Paracoccidioides brasiliensis. British Journal of Experimental Pathology, Londres, v.66, n.5, p.585-594, 1985.

CANO, L. E.; SINGER-VERMES, L. M.; VAZ, C. A. C.; RUSSO, M.; CALICH, V. L. G. Pulmonary paracoccidioidomycosis in resistant and susceptible mice: relationship among progression of infection, bronchoalveolar cell activation, cellular immune response, and specific isotype patterns. Infection Immunity, Washington, v.63, n.5, p.1777-1783, may 1995.

COELHO, K. I. R.; DEFAVERI, J.; IWASSO, M. T. R.; PERAÇOLI, M. T.; MOTA, N. G. S. Paracoccidioidomicose experimental. In: DEL NEGRO, G.; LACAZ, C. S.; FIORILLO, A. M. Paracoccidioidomicose blastomicose sul-americana. São Paulo: Sarvier-EDUSP, 1982. p.69-84. 
COUTINHO, Z. F.; SILVA, D.; LAZÉRA, M.; PETRI, V.; OLIVEIRA, R. M.; SABROZA, P. C.; WANKE, B. Paracoccidioidomycosis mortality in Brazil (1980-1995). Cadernos de Saúde Publica, Rio de Janeiro, v.18, n.5, p.1441-1454, 2002.

ITANO, E. N.; UNO, J.; SANO, A.; YARITA, K.; KAMEI, K.; MIYAJI, M.; NISHIMURA, K.; MIKAMI, Y. Detection of the gp43 gene and (1®3)-b-D-glucan of Paracoccidioides brasiliensis in the blood of experimentally infected mice. Japanese Journal of Medical Mycology, Tóquio, v.49, p.29-35, 2002.

LOWRY, O. H.; ROSOBROUGH, M. J.; FARR, A. L.; RANDALL, R. J. Protein measurement with the Folin phenol reagent. The Journal Biological Chemistry, Baltimore, v.246, p.1889-1894, 1971.

MENDES-GIANNINI, M. J. S.; BUENO, J. P.; SHIKANAIYASUDA, M. A.; STOLF, A. M. S.; MASUDA, A.; AMATO NETO, V.; FERREIRA, A.W. Antibody response to the $43 \mathrm{kDa}$ glycoprotein of Paracoccidioides brasiliensis as a marker for the evaluation of patients under treatment. The American Journal of Tropical Medical Hygiene, Baltimore, v.43, n.2, p.200-206, 1990.

MIURA, C. S. N.; LOPES, J. D.; ESTEVÃO, D.; ITANO, E. N. Levels of specific antigen (gp43), specific antibodies, and antigen-antibody complexes in saliva and serum of paracoccidioidomycosis patients. Medical Mycology; Oxford, v.39, n.5, p.423-28, oct. 2001.

PAVANELLI, W. R. Proteção induzida pelos componentes de alta massa molecular de Paracoccidioides brasiliensis em camundongos BALB/c. 2006. Dissertação (Mestrado em Patologia Experimental)-Universidade Estadual de Londrina, Londrina.

RAMOS, S. P.; SANO, A.; ONO, M. A.; CAMARGO, Z. P.; ESTEVÃO, D.; MIYAJI, M.; NISHIMURA, K.; ITANO, E. N. Antigenuria and antigenemia in experimental murine paracoccidioidomycosis. Medical Mycology; Oxford, v.43, p.631-636, 2005.
SALINA, M. A.; SHIKANAI-YASUDA, M. A.; MENDES, R. P.; BARAVIERA, B.; MENDES-GIANNINI, M. J. Detection of circulating Paracoccidioides brasiliensis antigen in urine of paracoccidioidomycosis patients before and during treatment. Journal of Clinical Microbiology, Washington, v.36, n.6, p.1723-1728, jun. 1998.

SANO, A.; MIYAJI, M.; NISHIMURA, K. Studies on the relationship between paracoccidioidomycosis in ddY mice and their estrus cycle. Mycophatologia, Boston, v.115, n.2, p.73-81, aug. 1991.

SILVA-VERGARA, M. L.; MARTÍNEZ, R. Inquérito epidemiológico com paracoccidioidina e histoplasmina em área agrícola de café em Ibiá, Minas Gerais, Brasil. Revista Iberoamericana de Micologia, Barcelona, v.15, p.294-297, 1998.

SINGER-VERMES, L. M.; CALDEIRA, C. B.; BURGER, E.; CALICH, V. L. G. Experimental murine paracoccidioidomycosis: relationship among the dissemination of the infection, humoral and cellular immune responses. Clinical and Experimental Immunology, Oxford, v.94, p.75-79, 1993.

SINGER VERMES, L. M; SAKAMOTO, T. N.; VAZ, C. A. C.; CALICH, V. L. G. Influence of genetic pattern and sex of mice in experimental paracoccidioidomycosis. Clinical and Experimental. Immunology, Oxford, v.101, n.1, p.114120, jul. 1995.

VAZ, C. A.C.; MACKENZIE, D. W. R.; HEARN, V. M.; CAMARGO, Z. P.; SINGER-VERMES, L. M.; BURGER, E.; CALICH, V. L. G. Specific recognition pattern of IgM and IgG antibodies produced in the course of experimental paracoccidioidomycosis. Clinical and Experimental. Immunology, Oxford, v.88, n.1, p.119-123, 1992.

VICENTINI, A. P.; GESZTESI, J. L.; FRANCO, M. M.; LOPES, J. D. Binding of Paracoccidioides brasiliensis to laminin through surface glycoprotein gp43 leads to enhancement of fungal pathogenesis. Infection Immunity, Washington, v.62, n.4, p.1465-1469, apr. 1995. 